\title{
The importance of shunt valve position in flow characteristics of the Medtronic PS Medical Delta valve
}

\section{Paul C. Francel, M.D., Ph.D., F. Alan Stevens, B.S., Paul Tompkins, M.S., and Michael Pollay, M.D.}

\begin{abstract}
Department of Neurosurgery, University of Oklahoma Health Sciences Center, Oklahoma City,
\end{abstract} Oklahoma

This study was conducted to document the extent to which flow depends on valve position in relation to head-pressure reference.

Medtronic PS Medical Delta valves (contour model, performance levels 0.5, 1.0, 1.5, and 2.0) were studied in a bench test designed to evaluate flow rates with respect to valve position in relation to the head-pressure reference postion. The valves were connected to an "infinite" reservoir by the standard inlet catheter. An initial head (proximal) pressure was selected for each valve based on package insert data. The position of the inlet catheter tip was fixed at this starting head pressure, thus making the inlet catheter tip position the reference for relative head pressures on the valve assembly. When the valve body is positioned above this level, the effective head pressure is lowered, and when the valve body is positioned below this level, the effective head pressure is raised. Flow was established with the siphon control portion of the valve body located on the same horizontal level as the inlet catheter tip (the reference head pressure or "0" position). A standard silastic catheter was attached to the outlet of the valve, and its length was fixed at $50 \mathrm{~cm}$ for all valves $\left(-50 \mathrm{~cm} \mathrm{H}_{2} 0\right)$. The distal end of the outlet catheter was connected to a fraction collector, and 1-minute samples (five replicates) were collected for gravimetric determination of flow rate. The valve assembly was then moved in 1-cm increments through the range of $4 \mathrm{~cm}$ above to $8 \mathrm{~cm}$ below the head-pressure reference position. Samples were collected from each position $(4 \mathrm{~cm}$ to $-8 \mathrm{~cm}$ ) relative to the inlet catheter tip. Flow rate, in milliliters/hour, was plotted against both relative position $(4 \mathrm{~cm}$ to $-8 \mathrm{~cm}$ ) and absolute head pressure (in centimeters of water).

Each of the valves tested was shown to have a linear relationship between flow and position relative to the inlet catheter tip (or absolute head pressure). The average increase in flow per centimeter of displacement of valve from catheter tip was $16.5 \mathrm{ml} / \mathrm{hr} / \mathrm{cm}$ (range 14.4-17.6 ml/hr/cm). Once the inlet catheter tip is fixed in position, it serves as a pressure reference. Movement of the valve above this level results in a net decrease in effective head pressure, and movement below this position results in a net increase in effective head pressure. Thus, the positioning of shunt valves in locations different from this pressure reference position should be performed only with the knowledge that significant increases in 
outflow rate may occur when the valve body is positioned lower than the inlet catheter tip. This increase in outflow rate is not the result of siphoning or a defect in the antisiphon device but instead the result of a net increase in effective head pressure.

\section{Key Words * shunt valve position * pressure-flow relationship * siphon * overdrainage}

There are currently numerous shunting systems available for use in the treatment of hydrocephalus. Overdrainage of cerebrospinal fluid (CSF) is a serious complication in patients in whom shunts have been placed.[2,5,7,10,11] Since the development of the antisiphon device (ASD) by Portnoy and Schulte in 1971, technology has advanced to the point at which many shunt valves have an integral siphon-control device (SCD). Such devices were intended to prevent overdrainage of the CSF compartment. There is, however, continuing controversy over the benefits of siphon-reducing devices. Reported findings range from "no significant benefit from the inclusion of a siphon control device (SCD) in the shunting system"[3] to the conclusion that "any form of ventriculoperitoneal shunt, with or without valves, with slit-end valves or cranial valves seemed to work equally well in the hands of a dedicated pediatric neurological surgeon."[8] One important factor in overdrainage, regardless of the valve type used, is the absolute position of the valve body itself with respect to the head-pressure reference position. Once the inlet catheter tip is fixed in place, it serves as the reference for effective head pressure on the inlet side of the valve assembly. All valve types, with or without SCDs, depend on intracranial pressure (ICP) to open the valve itself. However, when the valve body is placed significantly lower than the reference pressure location (for example, the foramen of Monro for the Delta valve), an effective increase of head pressure directly proportional to the distance between the inlet catheter tip and the location of the valve assembly will result. This effective increase in ICP most commonly occurs when the valve is located in the occipital region, although lesser misalignment can occur when using a frontal placement. This study was performed to underscore the importance of valve position with regard to the reference for ICP measurement (that is, the inlet catheter tip).

\section{MATERIALS AND METHODS}

Four types of Delta valves (performance level [PL] 0.5, 1.0, 1.5, and 2.0 [contour model; PS Medical, Goleta, CA]) were tested. We used commercially available inlet and outlet catheters with the valves, and the distal catheter length was fixed at $50 \mathrm{~cm}(-50 \mathrm{~cm}$ of siphon pressure). Three valves of each type were tested. Data used for averaging were from the first complete run of each valve type following valve wetting and establishment of stable flow. An "infinite" reservoir of sterile normal saline served as the source of the artificial ICP (head pressure). Fluid level in the reservoir was maintained by continuous addition of liquid to the predetermined height. Starting head pressures for each valve type were set as directed on the product inserts. Values were chosen such that each one started the test at its maximum suggested flow rate. The proximal catheter tip was fixed at a position in the reservoir in concert with the desired starting head pressure. The valve was affixed to a micrometer manipulator with the starting position equal to the desired head pressure (that is, horizontal with the tip of the proximal catheter). Five 1-minute outflow samples were collected in tared collection tubes, and the flow rate was determined gravimetrically. The results of preliminary experiments showed that the valves attained a constant flow rate within one sample of positioning. After collection of the fifth sample, the valve was repositioned via the micrometer adjustment in 1-cm increments. The range of positions was $4 \mathrm{~cm}$ above to $8 \mathrm{~cm}$ below the proximal catheter tip. The "0" position indicates the placement of the proximal catheter tip and the valve at the same level. This is the configuration suggested by Medtronic PS Medical for the contour Delta 


\section{RESULTS}

For all valve types a linear relationship between valve position and outflow rate was demonstrated. At the "0" position, each valve is open and flowing at least $50 \mathrm{ml} /$ hour. This was done so that each valve was flowing at a steady rate to avoid overcoming opening pressure. For each performance level, flow rate decreased as the valve was raised above the level of the proximal catheter tip $(0-4 \mathrm{~cm})$ and increased dramatically as the valve was positioned below the level of the inlet catheter tip $(0$ to $-8 \mathrm{~cm})$. Because the inlet catheter tip became the head-pressure reference position, increased flow rates were mandated when the valve assembly was positioned below this level. Figure 1 shows flow rate compared with the relative position for the PL 0.5, 1.0, 1.5, and 2.0 valves, respectively. Starting pressures were as follows: PL 0.5, $5 \mathrm{~cm} \mathrm{H}_{2} \mathrm{O}$; PL 1.0, $7 \mathrm{~cm} \mathrm{H} \mathrm{H}_{2} \mathrm{O}$ PL 1.5, $10 \mathrm{~cm} \mathrm{H}_{2} \mathrm{O}$; and PL 2.0, $15 \mathrm{~cm} \mathrm{H}_{2} \mathrm{O}$.
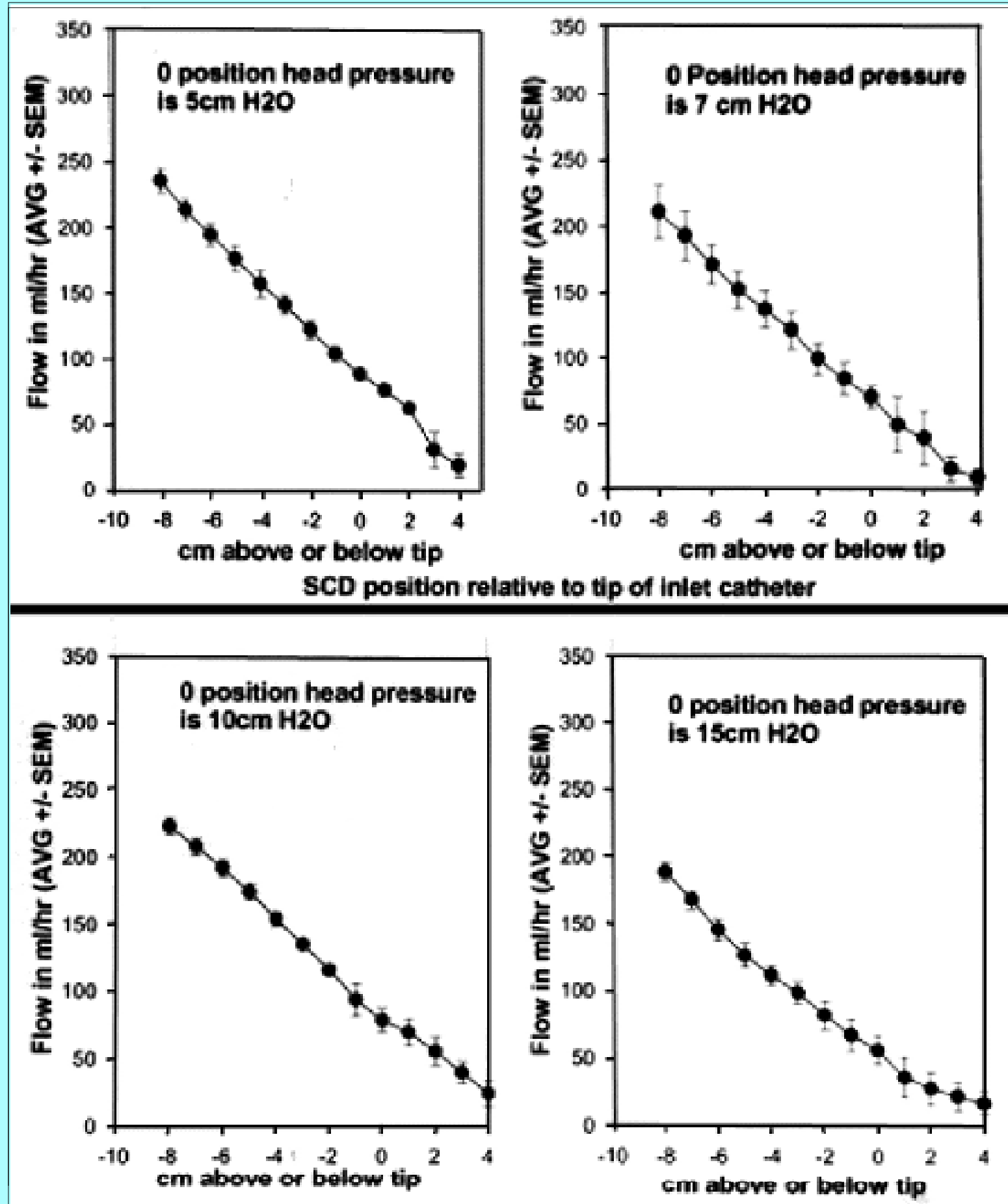
Fig. 1. Charts showing flow rates compared with shunt valve position relationships for Delta valves with PLs of 0.5 (a), 1.0 (b), 1.5 (c), and 2.0 (d). AVG = average; SEM = standard error of the mean.

Figure 2 shows the same flow data for all four valve types plotted against absolute head pressure (starting head pressure minus the hydrostatic pressure caused by valve position). This allows a direct comparison of the valves and also shows the effect of increasing valve resistance (for example, for a given flow rate, the PL 2.0 valve requires approximately $9 \mathrm{~cm}$ more pressure than the PL 0.5 valve).

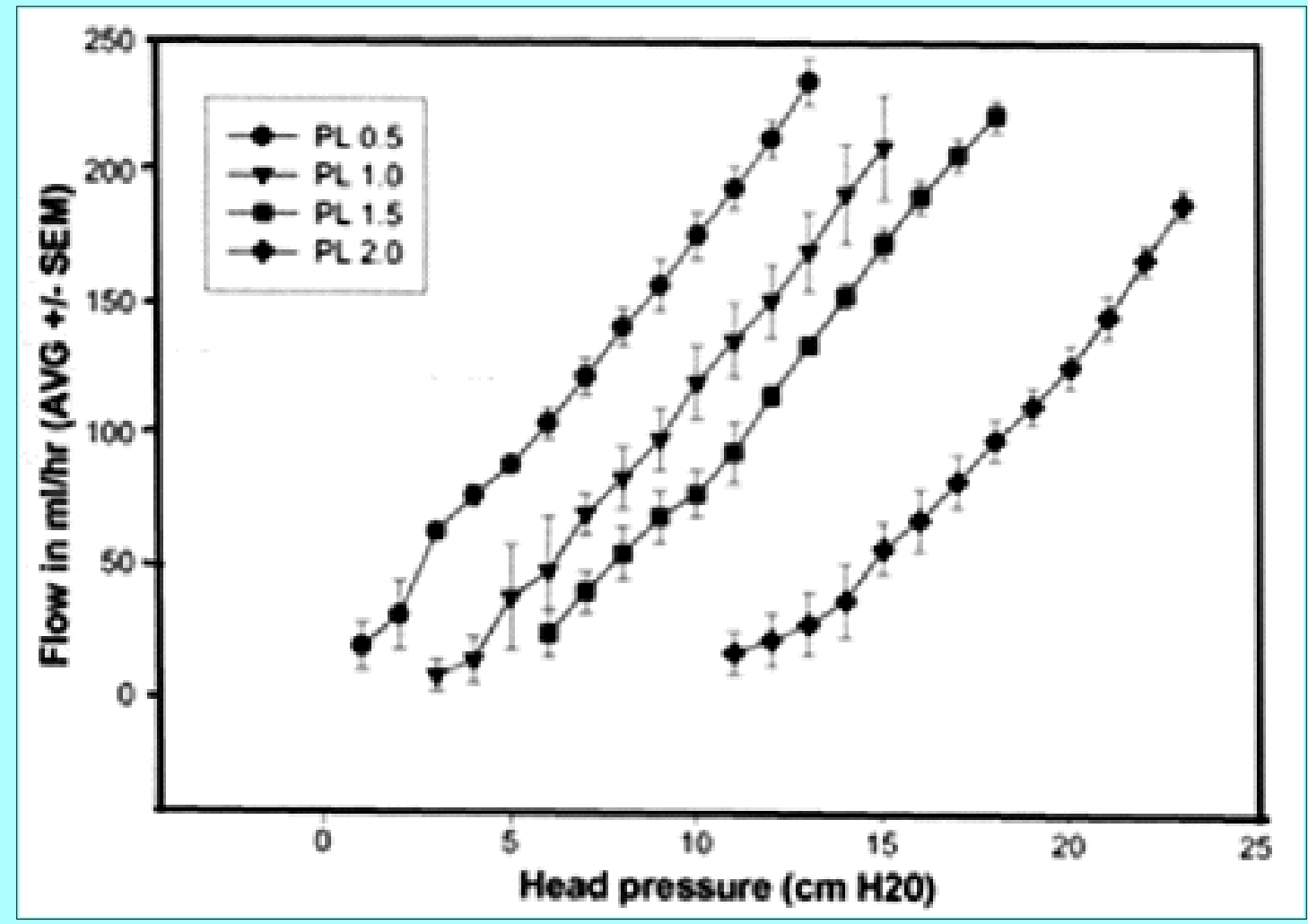

Fig. 2. Chart showing the relationship of flow rates compared with absolute head (perfusion) pressure for Delta valves with various PLs (see key).

The flow rates obtained within the usual range of operating pressures are in agreement with those reported in the literature.[7,11] Figure 3 shows the effect of $50 \mathrm{~cm}$ of outflow tubing (siphon pressure) on flow rate. The ratio between inlet diameter and the diameter of the SCD diaphragm is approximately $20: 1$, so that each $20 \mathrm{~cm}$ of outflow tubing adds $1 \mathrm{~cm}$ to the opening pressure. Over the range of operating pressures of the PL 1.0 valve, as shown in Fig. 3, the configuration with $50 \mathrm{~cm}$ outflow tubing requires approximately $2 \mathrm{~cm}$ more ICP to maintain the same flow as the configuration in which there is no outflow tubing. For all four valve types, flow varied directly with valve position relative to the proximal catheter tip (effective head pressure). Changes in flow per centimeter of head pressure were similar for all valve types (Table 1). 


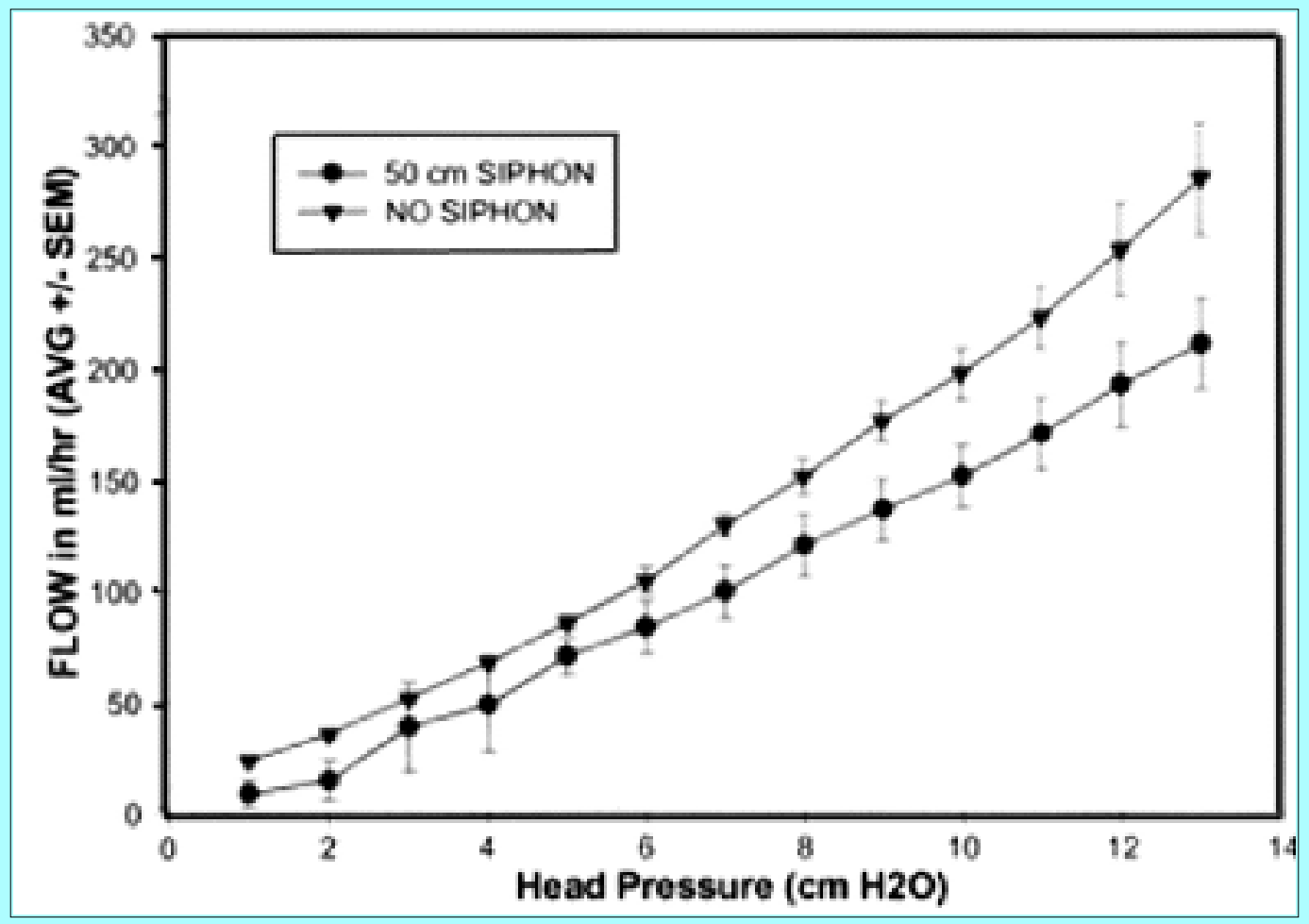

Fig. 3. Chart showing the relationship of flow rates for Delta valves (PL of 1.0) with and without siphons. Note that for a given flow rate, the addition of $50 \mathrm{~cm}$ of siphon pressure adds approximately $2 \mathrm{~cm}$ of pressure.

\begin{tabular}{|c|c|}
\hline \multicolumn{2}{|c|}{$\begin{array}{c}\text { TABLE } 1 \\
\text { OHANGES IN FLOW FOR ALL FOUR PL YALYES }\end{array}$} \\
\hline Val ve Type & Flow (mlikricm $\left.\mathrm{H}_{2} \mathrm{O}\right)^{+}$ \\
\hline $\begin{array}{l}\text { PL } 0.5 \\
\text { PL 1.0 } \\
\text { PL 1.5 } \\
\text { PL } 2.0\end{array}$ & $\begin{array}{l}17.6 ; r=0.99 \\
17.1 ; r=0.99 \\
16.9 ; r=0.98 \\
14.4 ; r=0.98\end{array}$ \\
\hline $\begin{array}{l}\text { "The flow ar } \\
\text { coefficient of }\end{array}$ & $\begin{array}{l}\text { slope and corre } \\
\text { slinear regress }\end{array}$ \\
\hline
\end{tabular}

\section{DISCUSSION}

The use of standard differential-pressure shunt valves carries significant risks of overdrainage of CSF when the patient is in the upright position. $[2,4,5,7,10,11]$ The use of an ASD should theoretically overcome this position-dependent overdrainage, but controversy continues over the benefit of such devices. Indeed, in a recent report the authors concluded that no significant benefit was obtained from the inclusion of an ASD or SCD in the shunt system.[3] Of equal importance is the conclusion that "any form of ventriculoperitoneal shunt, with or without valves, with slit-end valves or cranial valves seemed to work equally well in the hands of a dedicated pediatric neurological surgeon," which came from a paper reported in the same journal.[8] The function of the SCD is well documented in benchmark studies.[7] Although it is possible that an SCD may malfunction, leaving the valve to act as a differential-pressure valve, the most common complication related to the SCD is one of increased system resistance[1] and elevated ICP with underdrainage.[6] Although a variety of corrective actions have been proposed, including the use of any of the possible shunt systems, [8] servoregulated valves, $[9,12]$ and modification of the manufacturer's design to place the SCD 10 to $30 \mathrm{~cm}$ downstream from the 
flow-control valve, $[9,12]$ the question of overdrainage with a functional valve and SCD remains unanswered.

One important consideration in this dilemma is the physical positioning of the valve/SCD assembly with respect to the proximal catheter tip. Once this catheter tip is fixed in position, it becomes the reference position for head pressure (intraventricular pressure) on the inlet side of the shunt valve. The pressure available for driving flow across the shunt valve (perfusion pressure) may be seen as the sum of a number of pressures in the system:

$\mathrm{PP}=\mathrm{IVP}+\mathrm{HP}-(\mathrm{DCP}+\mathrm{CP})$

where PP is the perfusion pressure, IVP is the intraventricular pressure, HP is the hydrostatic pressure, DCP is the distal cavity (abdominal) pressure, and CP is the closing pressure of the differential-pressure valve. The closing pressure is fixed for a given valve type, and distal cavity pressure is generally taken to be $0 \mathrm{~cm} \mathrm{H} \mathrm{H}_{2} \mathrm{O}$, on average. Once the outflow catheter is fixed, the hydrostatic pressure is set and is compensated for by a properly functioning SCD. The remaining variable controlling shunt valve flow rate is IVP.

As recommended by Medtronic PS Medical, one reference location for IVP is the foramen of Monro. In practice, any reference location may be used, provided the valve/SCD and the reference point are maintained at the same level. Just as one determines arterial blood pressure by choosing the heart level as the reference, one must commit to a reference point when determining IVP. As the pressure transducer is moved higher than the reference location, the measured pressure decreases, and as it is moved lower the measured pressure increases. This is of course due to the effective hydrostatic pressure at the transducer (the distance between the reservoir and the transducer). In the case of shunts, the valve itself is the pressure-sensing system. Even in the case of the normally closed SCD, it is the ICP that drives flow in the system. By placing the valve/SCD below the level of the proximal catheter tip, one has effectively increased the ICP by an amount equal to the distance between the valve and the catheter tip.

In this study we evaluated the effect of varying valve/SCD position in relation to the proximal catheter tip. Analysis of the data uniformly shows significant increases in outflow as the valve system is moved below the level of the catheter tip. For the four types of Delta valve investigated, displacement of the valve by as much as $3 \mathrm{~cm}$ negative to the proximal catheter tip would result in flow rates sufficient to cause overdrainage before the valve closed. The magnitude of this effect depends only on the overall vertical displacement between the valve and the inlet catheter tip.

\section{CONCLUSIONS}

The fluid dynamics of shunt valve operation are complex and dependent on many factors, including patency of both proximal and distal catheters, patency of the valve itself, and the proper functioning of the SCD. The results of this study indicate the importance of the hydrodynamic relationship between the valve assembly and the reference point in measuring IVP. The SCDs functioned properly, but the valves were allowed to act as differential pressure valves by effectively increasing head pressure. Extreme care should be taken when implanting these valves in positions other than with the SCD and the tip of the inlet catheter at the same reference location (usually the foramen of Monro). When the contour model Delta valves are placed in the occipital area overdrainage is clearly possible, particularly in adults in whom the distance between inlet catheter tip and the valve assembly may be at a maximum. If an occipital placement is desired, a burr hole model of the Delta valve is available. Within its chassis, this 
valve also contains an SCD, and the burr hole placement assures alignment at the same level as the horizontally placed ventricular catheter.

\section{References}

1. Aschoff A, Kremer P, Benesch C, et al: Overdrainage and shunt technology. A critical comparison of programmable, hydrostatic and variable-resistance valves and flow-reducing devices. Childs Nerv Syst 11:193-202, 1995

2. Chapman PH, Cosman ER, Arnold MA: The relationship between ventricular fluid pressure and body position in normal subjects and subjects with shunts: a telemetric study. Neurosurgery 26:181-189, 1990

3. Drake JM, Kestle J: Rationale and methodology of the multicenter pediatric cerebrospinal fluid shunt design trial. Childs Nerv Syst 12:434-447, 1996

4. Fox JL, McCullough DC, Green RC: Effect of cerebrospinal fluid shunts on intracranial pressure and on cerebrospinal fluid dynamics. 2. A new technique of pressure measurements: results and concepts. 3. A concept of hydrocephalus. J Neurol Neurosurg Psychiatry 36:302-312, 1973

5. Gruber R, Jenny P, Herzog B: Experiences with the anti-siphon device (ASD) in shunt therapy of pediatric hydrocephalus. J Neurosurg 61:156-162, 1984

6. Hassan M, Higashi S, Yamashita J: Risks in using siphon-reducing devices in adult patients with normal-pressure hydrocephalus: bench test investigations with Delta valves. J Neurosurg 84:634-641, 1996

7. Horton D, Pollay M: Fluid flow performance of a new siphon-control device for ventricular shunts. $\mathbf{J}$ Neurosurg 72:926-932, 1990

8. James HE, Bruce DA: Ventriculoperitoneal shunts for hydrocephalus: a focus group discussion on the selection of shunt systems in pediatrics. A report of the Pediatric Neurosurgery Research Group meeting, December 1992. Childs Nerv Syst 11:449-452, 1995

9. McCullough DC: Symptomatic progressive ventriculomegaly in hydrocephalics with patent shunts and antisiphon devices. Neurosurgery 19:617-621, 1986

10. McCullough DC, Fox JL: Negative intracranial pressure hydrocephalus in adults with shunts and its relationship to the production of subdural hematoma. J Neurosurg 40:372-375, 1974

11. Portnoy HD, Schulte RR, Fox JL, et al: Anti-siphon and reversible occlusion valves for shunting in hydrocephalus and preventing post-shunt subdural hematomas. J Neurosurg 38:729-738, 1973

12. Tokoro K, Chiba Y: Optimum position for an anti-siphon device in a cerebrospinal fluid shunt system. Neurosurgery 29:519-525, 1991

13. Watson DA: The Delta Valve: a physiologic shunt system. Childs Nerv Syst 10:224-230, 1994

Manuscript received August 15, 1999. 
Accepted in final form September 22, 1999.

This study was supported by funds from Medtronic PS Medical.

Address reprint requests to: Paul C. Francel, M.D., Department of Neurosurgery, University of Oklahoma, HSC, 711 SL Young Blvd, Suite 206, Oklahoma City, Oklahoma 73104. email: Paul-Francel@ouhsc.edu. 